OPEN ACCESS

Edited by:

Linda Chang,

University of Maryland, Baltimore

United States

Reviewed by:

Ronald J. Ellis,

University of California, San Diego,

United States

Ian A. Simpson,

Pennsylvania State University,

United States

${ }^{*}$ Correspondence:

Valerie Wojna

valerie.wojna1@upr.edu

tThese authors have contributed equally to this work and share first

authorship

Specialty section: This article was submitted to Neuroinfectious Diseases, a section of the journal

Frontiers in Neurology

Received: 20 August 2018 Accepted: 05 March 2019

Published: 26 March 2019

Citation:

Gerena Y, Menéndez-Delmestre $R$ Delgado-Nieves A, Vélez J,

Méndez-Álvarez J, Sierra-Pagan JE,

Skolasky RL, Henderson L, Nath A and Wojna V (2019) Release of

Soluble Insulin Receptor From Neurons by Cerebrospinal Fluid From

Patients With Neurocognitive

Dysfunction and HIV Infection.

Front. Neurol. 10:285.

doi: 10.3389/fneur.2019.00285

\section{Release of Soluble Insulin Receptor From Neurons by Cerebrospinal Fluid From Patients With Neurocognitive Dysfunction and HIV Infection}

\author{
Yamil Gerena ${ }^{1 \dagger}$, Raissa Menéndez-Delmestre ${ }^{2 \dagger}$, Andrea Delgado-Nieves ${ }^{1}$, Joyce Vélez ${ }^{2}$, \\ Jarold Méndez-Álvarez ${ }^{3}$, Javier E. Sierra-Pagan ${ }^{1}$, Richard L. Skolasky ${ }^{4}$, Lisa Henderson ${ }^{5}$, \\ Avindra Nath ${ }^{5}$ and Valerie Wojna ${ }^{6 *}$
}

${ }^{1}$ NeuroHIV Research Program, Department of Pharmacology and Toxicology, School of Medicine, University of Puerto Rico, Medical Sciences Campus, San Juan, PR, United States, ${ }^{2}$ NeuroHIV Research Program, University of Puerto Rico, Medical Sciences Campus, San Juan, PR, United States, ${ }^{3}$ Internal Medicine Residency Program, Damas Hospital, Ponce, PR, United States, ${ }^{4}$ Department of Orthopaedic Surgery, Johns Hopkins University, Baltimore, MD, United States, ${ }^{5}$ Section of Infections of the Nervous System, National Institute of Neurological Disorders and Stroke, National Institutes of Health, Bethesda, MD, United States, ${ }^{6}$ NeuroHIV Research Program, Division of Neurology, Internal Medicine Department, University of Puerto Rico, Medical Sciences Campus, San Juan, PR, United States

Previously, we found that high levels of soluble insulin receptor (sIR) in the cerebrospinal fluid (CSF) of an HIV-infected women cohort were associated with the presence and severity of HIV-associated neurocognitive disorders (HAND). In this study we investigated if CSF from this population, HIV-1 Tat, and selected cytokines induces sIR secretion from human neuronal cells. Twenty-three (23) HIV-seropositive women stratified by cognitive status and five HIV- seronegative women were evaluated. Soluble IR levels were measured in the extracellular medium of neuronal cells (SH-SY5Y) that were exposed (for $24 \mathrm{~h}$ ) to the CSF of patients. The levels of sIR, HIV-1 Tat, and cytokine levels (IL-2, $I L 4, I L-6, I F N \gamma$, TNF $\alpha$, and IL-10) were quantified in the CSF of participants by ELISA and flow cytometry. Neuronal secretion of sIR was measured after exposure (24 h) to HIV-1 Tat (0.5-250 nM), or specific cytokines. The effects of TNF $\alpha$ and HIV-1 Tat on sIR secretion were also evaluated in the presence of R7050 (TNF $\alpha$ antagonist; $10 \mathrm{nM}$ ). Neurons exposed to the CSF of HIV-infected women had higher sIR levels according to the severity of neurocognitive impairment of the participant. Increased CSF sIR levels were associated with the presence and severity of HAND and were positively correlated with CSF HIV-1 Tat levels in HIV-infected women with cognitive impairment. CSF levels of IL-2, IFN $\gamma$, and TNF $\alpha$ were significantly increased with HAND. However, only TNF $\alpha$ (5 $\mathrm{pg} / \mathrm{mL})$ and HIV-1 Tat $(100 \mathrm{nM})$ induced a significant increase in neuronal sIR secretion after $24 \mathrm{~h}$ exposure, an effect that was antagonized when each were combined with R7050. Our data suggests that TNF $\alpha$ and HIV-1 Tat from the CSF of HIV-infected women may regulate the secretion of sIR from neuronal cells and that the effect of HIV-1 Tat on sIR secretion may depend on TNF $\alpha$ receptor activation.

Keywords: receptor, insulin, tumor necrosis factor, HIV tat protein, insulin resistance, cognitive dysfunction, female 


\section{INTRODUCTION}

Chronic inflammation in HIV-infected individuals has been associated with insulin resistance, cardiovascular diseases, thrombosis, muscle wasting, neurocognitive impairment, renal and liver diseases, obesity, and premature aging (1-10). Constant production of viral proteins (Tat, Nef, and gp120) and elevated pro-inflammatory cytokine levels (TNF $\alpha$, IL-1 $\beta$, IL-6, and IL-8) contribute to persistent neuroinflammation and are associated with cognitive impairment in HIV-infected patients $(9,11-17)$.

HIV-1 Tat is continuously produced in patients even in the presence of viral suppression, thus promoting the persistence of chronic inflammation in both the peripheral and the central nervous system (18). HIV-1 Tat protein is known to induce $\mathrm{TNF} \alpha$ production and high levels of this cytokine are present throughout all stages of HIV infection $(19,20)$. Although essential for the innate immune response to acute inflammation, persistent elevated levels of TNF $\alpha$ contribute to the maintenance of the chronic neuroinflammation observed in HIV-infected patients. These prolonged high levels of TNF $\alpha$ can lead to glutamate-mediated neuronal toxicity (21) as well as stimulate the release of neurotoxic factors, and cell signaling cascades that lead to neuronal dysfunction and death $(13,20,22,23)$. The combined neuronal damage of viral proteins and cytokines is implicated in the pathogenesis of HIV-associated neurocognitive disorders (HAND) (24-28).

Overproduction of pro-inflammatory cytokines has also been implicated in the pathophysiology of insulin resistance and metabolic disorders $(29,30)$. TNF $\alpha$ can mediate metabolic abnormalities in different tissues by inducing serine phosphorylation of insulin receptor substrate-1 (IRS-1) protein, decreasing the expression of insulin signaling molecules, and down-regulating the expression of the insulin regulated glucose transporter, GLUT $4(29,31,32)$. Insulin receptor is expressed on the surface of neurons and its activation can lead to increased neurite growth, gene expression, and energy metabolism. IRS-1 is the major substrate of the insulin receptor (33). Abnormalities in this pathway have been linked with neurodegeneration including Alzheimer's disease (34). However, its role in the pathophysiology of HAND has not been explored.

It is known that people living with HIV (PLH) may develop insulin resistance, HAND, or both, as a result of chronic HIV infection, long-term use of combined antiretroviral therapy (cART), aging, genetic predisposition, or a combination of these factors (35-37). Thus, identification of molecular and cellular pathways linking the high incidence of insulin resistance and HAND in PLH is crucial. Defects in the insulin receptor signaling pathway represents a major target for modulating critical energy functions such as glucose and lipid metabolism, neuronal growth and survival, and synaptic plasticity (38-40). Recently, we showed that high plasma and CSF soluble insulin receptor (sIR) levels are associated with the presence and severity of HAND in a cohort of HIV-infected women on cART $(41,42)$. Moreover, we observed an increased binding of plasma insulin to sIR in patients with worse cognitive performance (42). Hence, there is a need to identify the factors that contribute to the secretion of sIR into the CSF. In this study, we investigated if the CSF from
HIV-infected women with HAND influences the secretion of sIR from human neuronal cells. In addition, we evaluated whether this secretion was regulated by HIV-1 Tat protein, TNF $\alpha$, or other selected cytokines.

\section{MATERIALS AND METHODS}

\section{Participants and Study Design}

This was a retrospective cross-sectional study using patientdatabase information and the sample repository of the HispanicLatino Longitudinal Cohort of Women. This study was approved by the University of Puerto Rico Medical Sciences Campus (UPRMSC) Institutional Review Board, and all the participants signed a written informed consent. This is a unique cohort of Hispanic $\mathrm{HIV}$-infected women characterized longitudinally with viral and immune profiles, neurological exams, and neuropsychological tests. Twenty-four HIV-infected women without a history of diabetes and $5 \mathrm{HIV}$-seronegative controls were evaluated, as described previously (41-43). Cognitive impairment was determined using the HAND nosology (44). The HIV-infected women were grouped according to their cognitive performance as having normal cognition ( $\mathrm{NC} ; n=11$ ), asymptomatic impairment (AI; $n=4)$, and symptomatic impairment [SI, mild neurocognitive disorder (MND) plus HIV-associated dementia (HAD); $n=9]$.

When the HIV-infected women were grouped by cognitive performance, no significant differences were observed between groups with regard to age, body mass index (BMI), current CD4 cell count, CSF and plasma viral load, co-infection with the hepatitis $\mathrm{C}$ virus, or toxicology $(p>0.05)$. Most HIV-infected women were using antiretroviral therapy (ART) $(82.6 \%$, or 19 of the 23 women) with protease inhibitors $(84 \%$, or 16 of the 19 women taking ART). There was no significant difference between groups of increasing HAND severity in either use of ART, protease inhibitor, nor CNS Penetration Effect [using scale prepared by Dr. Scott Letendre (45) $(p>0.05)$ Table 1].

\section{Participant's CSF and Neuronal Cells CSF Sample Preparation and sIR Depletion}

All spinal taps were performed by the same neurologist (VW) using an atraumatic Sprotte needle. CSF was centrifuged at 130 $\times \mathrm{g}$ for $10 \mathrm{~min}$ at $4^{\circ} \mathrm{C}$, and cell pellets and supernatants were separated. Aliquots of supernatant were stored at $-80^{\circ} \mathrm{C}$. CSF samples tested negative for VDRL. Soluble IR present in the CSF of HIV-infected women and controls were removed prior to incubation with neuronal cells. Aliquots $(200 \mu \mathrm{l})$ of CSF samples were incubated with anti-hIR $\beta$-specific monoclonal antibodyprotein A-Sepharose beads for $16 \mathrm{~h}$ at $4^{\circ} \mathrm{C}$ with gentle agitation. Depleted CSF samples were analyzed using ELISA [27, 29] to confirm the absence of all sIR in the CSF of all the participants.

\section{Treatment of Neuronal Cells With CSF}

Human neuronal cells (SH-SY5Y; ATCC, Manassas, VA) were grown $\left(5 \times 10^{5}\right.$ cells/well $)$ in 24 -well plates supplemented with $10 \%$ FBS and $1 \%$ penicillin-streptomycin in EMEM growth medium at $37^{\circ} \mathrm{C}$ and $5 \% \mathrm{CO}_{2}$. After allowing the cells to adhere overnight, medium was removed and replaced with sIR-depleted 
TABLE 1 | Characteristics of HIV-infected women.

\begin{tabular}{|c|c|c|c|c|}
\hline & $\begin{array}{l}\text { Normal cognition } \\
\qquad N=11\end{array}$ & $\begin{array}{c}\text { Asymptomatic } \\
\qquad N=4\end{array}$ & $\begin{array}{c}\text { Symptomatic } \\
\qquad=9\end{array}$ & $p$-value \\
\hline Age (years) & $44(30 ; 46)$ & $38(35 ; 42)$ & $43(42 ; 46)$ & 0.123 \\
\hline CD4 (cells/mm³) & $420.0(254.8 ; 573.3)$ & $490.0(399.5 ; 588.8)$ & $315.0(264.5 ; 474.5)$ & 0.375 \\
\hline CSF HIV RNA (log) & $1.70(1.70 ; 2.59)$ & $1.98(1.70,2.27)$ & $1.70(1.70,1.90)$ & 0.562 \\
\hline Plasma HIV RNA (log) & $3.12(1.70 ; 3.45)$ & $2.73(1.93 ; 3.37)$ & $1.76(1.70,2.46)$ & 0.126 \\
\hline Hepatitis C virus (\% positive) & $4 / 10(40 \%)$ & $2 / 4(50 \%)$ & $1 / 8(12.5 \%)$ & 0.335 \\
\hline Body mass index & $28.18(25.9 ; 32.4)$ & $22.68(20.95 ;-)$ & $27.49(22.43,30.37)$ & 0.204 \\
\hline Toxicology (\% positive) & $0 / 9(0 \%)$ & 2/4 (50\%); marijuana & 2/9 (22.2\%); cocaine & 0.100 \\
\hline Antiretroviral therapy (\% positive) & $8 / 10(80 \%)$ & $3 / 4(75 \%)$ & $8 / 9(89 \%)$ & 0.804 \\
\hline Protease inhibitors (\% positive) & $6 / 8(75 \%)$ & 2/3 (66.7\%) & $8 / 8(100 \%)$ & 0.278 \\
\hline CNS penetration effect & $7(6 ; 7)$ & $6(3 ; 7)$ & $7(6 ; 7)$ & 0.484 \\
\hline
\end{tabular}

Median (25th, 75th percentile).

CSF $(200 \mu \mathrm{l})$ from each HIV-infected patient and controls for $24 \mathrm{~h}$. To determine cell viability after incubation with CSF overnight, we performed a MTT assay. Our data demonstrated that cell viability was above $95 \%$ after incubation with the CSF (data not shown). The levels of sIR in the CSF were determined by ELISA [27, 29].

\section{CSF HIV-1 Tat and Cytokine Levels}

HIV-1 Tat levels were measured in the CSF of HIV-infected women $(n=20)$ by sandwich ELISA as described previously (46) at Dr. Avindra Nath's laboratory (NIH-NINDS). Data represent average value of samples run in triplicate on two separate ELISA plates.

The human TH1/TH2 Cytometric Bead Array (CBA) kit (BD Biosciences Pharmingen, San Diego, CA) was used to determine the levels of IL-2, IL-4, IL-6, IL-10, IFN $\gamma$, and TNF $\alpha$ in the CSF of HIV-infected women and HIV-seronegative controls. With the CBA, different bead populations with distinct fluorescence intensities had been coated with capturing antibodies specific for different cytokines. After incubation with $50 \mu \mathrm{L}$ of CSF, the cytokine-captured beads were mixed with phycoerythrinconjugated detection antibodies to form sandwich immunecomplexes. Cytokine levels were performed blinded to group cognitive status and analyzed by flow cytometry.

\section{Treatment of Neuronal Cells With Cytokines or HIV-1 Tat Protein}

The physiological levels of cytokines in the CSF of HIV-infected women were quantified by flow cytometry, as described above. Cytokines (TNFa: 5 pg/mL, IL-2: 2 pg/mL, IL-6: 10 pg/mL, IL10: $2 \mathrm{pg} / \mathrm{mL}$, or IFN $\gamma: 2 \mathrm{pg} / \mathrm{mL}$ ) were added individually to the culture medium of SH-SY5Y neurons for a period of $24 \mathrm{~h}$ at $37^{\circ} \mathrm{C}$ and $5 \% \mathrm{CO}_{2}$. Cells were also exposed to different HIV1 Tat concentrations $(0.5-250 \mathrm{nM})$ for $24 \mathrm{~h}$. The secreted sIR levels were analyzed by ELISA. In other experiments, secreted sIR levels were determined after incubation with $\mathrm{TNF} \alpha(5 \mathrm{pg} / \mathrm{ml})$ or HIV-Tat protein $(100 \mathrm{nM})$ in the presence of R7050 $\left(10^{-8} \mathrm{M}\right)$.

\section{Determination of the Soluble Insulin Receptor}

Soluble insulin receptor full-length ( $\operatorname{siR}-\alpha \beta$, intact) levels methods were previously determined and published $(41,42)$. Briefly, levels were determined by incubating with an anti-IR ectodomain antibody $(1: 1,000)$ (Abcam, Cambridge, MA) for $2 \mathrm{~h}$ at $20^{\circ} \mathrm{C}$ and a FITC-secondary antibody (Abcam, Cambridge, MA). Samples were analyzed in a Cytofluor 4000 (Applied Biosystems, CA) using 485/530 nm excitation/emission filters. The method used to quantify sIR is only capable of detecting intact full-length receptors by ELISA using a capture antibody specific for the amino acids near to the C-terminal of the beta subunit and a primary antibody near to the N-terminal of the alpha ectodomain (41).

\section{Flow Cytometry}

All the flow cytometric analyses were carried out using a FACSCalibur cytometer (BD Biosciences, CA). CellQuest software (BD Biosciences, CA) was used for data acquisition and multivariate analysis. Cells were gated in forward/side scatter dot plots. PE emissions from cytokines were measured in the FL2 (585 nm band-pass filter) channel. Data on scatter parameters and histograms were acquired in log mode. Ten thousand events were evaluated for each sample, and the median peak channel obtained from the histograms was used to determine the levels of CSF cytokines.

\section{Statistical Analyses}

We compared sIR, cytokine, and HIV-1 Tat levels in the CSF of four groups: the control group and the groups of HIV-infected women stratified by cognitive impairment as having normal cognition (NC), asymptomatic impairment (AI), or symptomatic impairment (SI). Because the data were not normally distributed, these comparisons were made using non-parametric analyses. The control group consisted of 5 CSF samples. The use of 5 control samples was adequate to estimate the median and interquartile range. Nonparametric analysis was performed to compare sIR levels 
secreted from cultured neurons exposed to the CSF of HIVinfected women (stratified by HAND severity) and controls. Parametric one-way ANOVA analysis were used to compare neuronal sIR secretion after exposure to selected cytokines, HIV-Tat protein or combinations with and without R7050. All statistical analyses were performed with IBM SPSS Statistics (version 24) and GraphPad Prism 7. Statistical significance was considered $p<0.05$.

\section{RESULTS}

\section{Soluble Insulin Receptor (sIR) Levels in the CSF of HIV-Infected Women}

Soluble IR levels were quantified in the CSF of HIV-infected women and HIV-seronegative controls. The levels of sIR were significantly increased in HIV-infected women relative to those of the controls $(p=0.002)$. When HIV-infected women were stratified by HAND, higher levels of CSF sIR were associated with the presence $(p=0.018)$ and increased severity of HAND $(p=0.010$; Figure 1A). A two-way ANOVA including HAND status, age, and their interaction was used. These covariates did not change the relationship between CSF sIR levels and HAND status.

\section{sIR Secretion From Neuronal Cells Exposed to the CSF of HIV-Infected Women}

Prior to incubating SH-SY5Y neuronal cell culture with the CSF of HIV-seronegative and HIV-infected women, the CSF was successfully depleted of sIR. After $24 \mathrm{~h}$ of incubation, sIR secretion was significantly higher in neurons exposed to CSF from HIV-infected women relative to those exposed to CSF from HIV-seronegative controls $(p=0.016)$. When the CSF of HIV-infected women was stratified by HAND, higher levels of full-length sIR secreted from neuronal cells were associated with the presence $(p=0.004)$ and severity of HAND ( $p=$ 0.035; Figure 1B).

\section{HIV-1 Tat Levels in the CSF of HIV-Infected Women}

HIV-1 Tat levels were measured in the CSF of HIV-infected women $(n=20)$ by sandwich ELISA as described previously (46). CSF HIV-1 Tat levels were undetectable in two of the participants irrespective of their plasma viral load or their HAND diagnostic. When controlling for CSF/plasma ratio of HIV RNA viral load, we observed a significant positive correlation between CSF Tat and CSF $\operatorname{sIR}$ among those with symptomatic HAND $(n=11 ; p=$ 0.010; Figure 2).

\section{Cytokine Levels in the CSF of HIV-Infected Women}

The levels of IL-2, IL4, IL-6, IFN $\gamma, \mathrm{TNF} \alpha$, and IL-10 were quantified in the CSF of HIV-infected women and controls. Significantly increased levels in the CSF of inflammatory cytokines IL-2 $(p=0.002)$, IFN- $\gamma(p=0.002)$, and TNF- $\alpha$ $(p=0.009)$ were associated with the presence and severity of

\section{A sIR Levels in CSF}

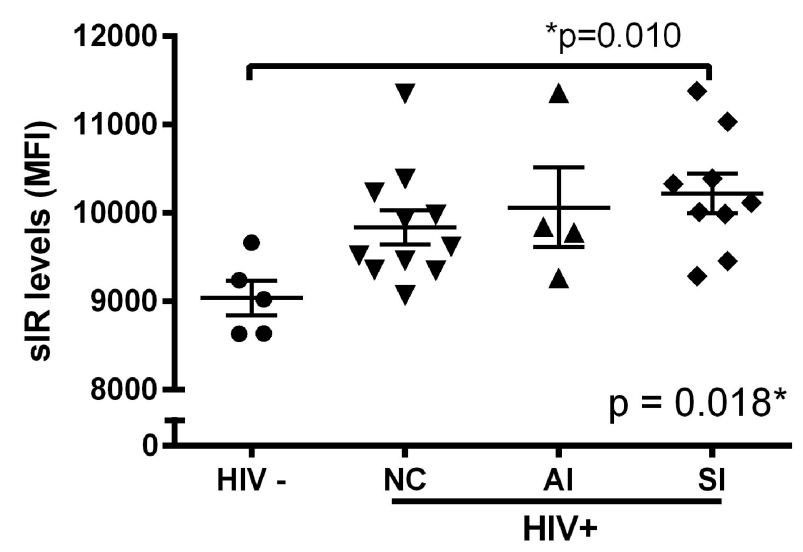

B SIR Levels secreated by neurons after incubation with patients' CSF

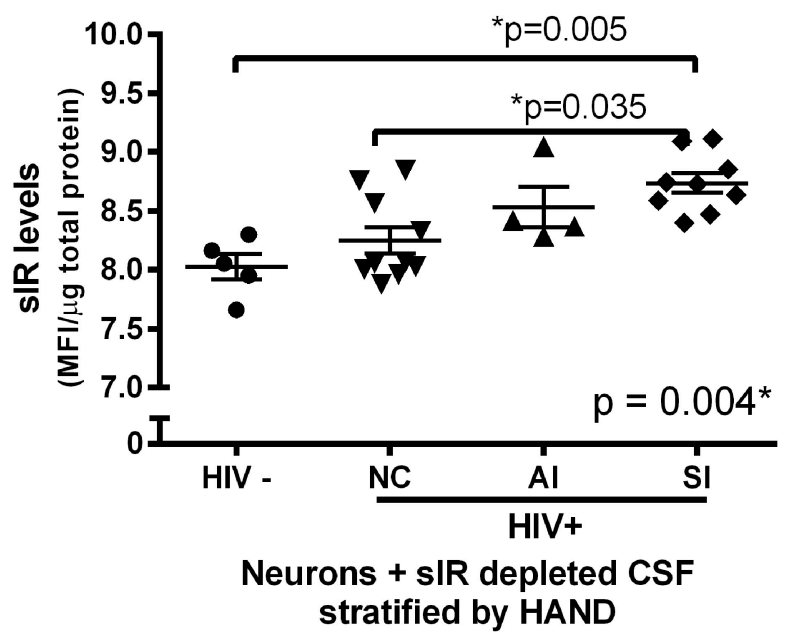

FIGURE 1 | Soluble insulin receptor (SIR) levels in the CSF of patients and neuronal SIR release by neurons after incubation with CSF of HIV-infected women with HAND. (A) Higher CSF sIR levels were associated with the presence and increased severity of HAND (HIV-: $\bullet, n=5$; NC: $\mathbf{\nabla}, n=11$; Al: $\mathbf{\Delta}, n=4$; SI: $\wedge=9$ ). Scattered dots show the CSF sIR levels of each participant. Horizontal and vertical lines represent mean \pm SEM. (B) When stratified by HAND severity (NC: $\mathbf{\nabla}, n=11$; Al: $\mathbf{\Lambda}, n=4$; SI:,$n=9$ ), higher levels of sIR secreted from neuronal cells were associated with the presence and severity of HAND. Scattered dots show the secreted sIR levels quantified from each CSF participant. Horizontal and vertical lines represent mean \pm SEM.

HAND (Figures 3A-C). Although no significant difference was observed with CSF levels of IL-6 $(p=0.061)$, a significant difference was observed between HIV-infected women with normal cognition and those with symptomatic neurocognitive impairment in a post-hoc analysis $(p=0.044$, Figure 3D). No significant differences were found in the CSF levels of IL-4, or IL-10 between HIV-seronegative controls and HIV-infected women stratified by HAND ( $p>0.05$, Figures 3E,F). When controlling for CSF/plasma ratio of HIV RNA viral load, we 


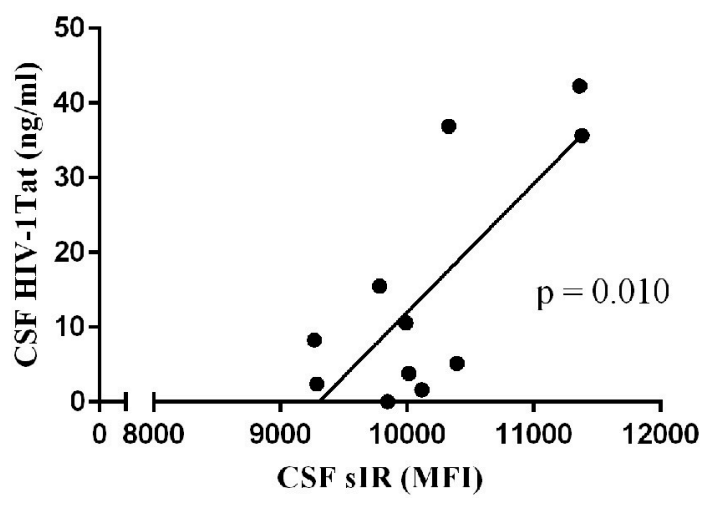

FIGURE 2 | HIV-1 Tat levels in the CSF correlates positively with CSF SIR levels of cognitively impaired HIV-infected women. HIV-1 Tat levels were measured in the CSF of $20 \mathrm{HIV}$-infected women. When controlling for CSF/plasma ratio of HIV RNA viral load, we observed a significant positive correlation between CSF Tat and CSF sIR among those with symptomatic $\operatorname{HAND}(\bullet ; n=11)$. Data represent average value of samples run in triplicate on two separate ELISA plates.

observed no significant correlation between CSF HIV-1 Tat and CSF cytokines. However, a positive correlation was observed between CSF sIR levels and IL-10 ( $p=0.013$; data not shown).

\section{Neuronal sIR Levels After Cytokine or HIV-1 Tat Treatment}

Neuronal sIR secretion was measured in the culture medium after $24 \mathrm{~h}$ incubation with some of the cytokines previously quantified in the CSF of HIV-infected patients (IL-2, IL-6, IFN- $\gamma$, $\mathrm{TNF} \alpha$, and IL-10). Among these cytokines only $\mathrm{TNF} \alpha$ was able to significantly increase the levels of sIR secreted from neurons compared to those untreated ( $p=0.036$; Figure 4).

We conducted a dose-response curve of HIV-1 Tat $(0,0.5$, $1,10,50,100$, and $250 \mathrm{nM}$ ) to determine the dose that would induce maximal sIR secretion by neurons. We observed a dosedependent effect of HIV-1 Tat on sIR secretion with maximal response at $100 \mathrm{nM}$ concentration ( $p<0.001$; Figure 5).

HIV-1 Tat protein is known to induce the production of TNF $\alpha$ in cells derived from brain tissue (44). To determine whether HIV-1 Tat increased neuronal secretion of sIR via activation of TNF $\alpha$ receptors, we incubated the cells for $24 \mathrm{~h}$ with HIV-1 Tat $(100 \mathrm{nM})$ or TNF $\alpha(5 \mathrm{pg} / \mathrm{mL})$ in the presence of the TNF $\alpha$ antagonist, R7050 (10 nM). Incubation with either HIV-1 Tat or $\mathrm{TNF} \alpha$ significantly increased the secretion of sIR by neuronal cells. However, these effects were antagonized by the addition of R7050 to the extracellular medium ( $p<0.001$; Figure 6).

\section{DISCUSSION}

The mechanisms involved in the pathophysiology of insulin resistance and cognitive impairment in HIV-infected participants remain unclear. Several mechanisms may explain the generation of the CSF sIR, including secretion from astrocytes, neurons, or PBMCs that cross the blood-brain barrier (BBB), brain tissue injury, or plasma sIR that crosses the BBB (41). We previously showed that higher levels of plasma and CSF sIR full-length were associated with HAND in a population of HIV-infected women (41). In addition, we observed that plasma sIR served as a scavenger receptor through the binding of higher percentages of insulin in patients with the severe forms of HAND (42). These findings suggest that changes in plasma sIR could be associated with an asymptomatic glucose derangement and may contribute to the development of insulin resistance and HAND (41). The observation of a significant IRS-1 tyrosine phosphorylation decrease suggests the possibility of chronic subclinical cellular insulin resistance, which could contribute to the development of HAND (38).

Although the generation of intact and other sIR isoforms was observed in several cultured cell lines (47), their secretion from neuronal cells has never been explored. In our study we exposed human neuronal SH-SY5Y cells to the CSF of HIVinfected women and found that these cells secreted higher sIR levels compared to the CSF of HIV-seronegative controls. When stratified by cognitive status, this increased secretion was associated with the severity of HAND. The mediators that contributed to this secretion were unknown. Thus, identifying the factors that influence the secretion of sIR to the CSF may help in the development of novel strategies for early intervention and, possibly, the prevention of insulin resistance progression and HAND in this population.

Increasing evidence suggests that inflammation is actively involved in the neuropathogenesis of HAND, and several cytokines have been identified as potential contributors. The importance of these cytokines, especially $\mathrm{TNF} \alpha$, has been emphasized in the propagation and maintenance of a CNS inflammatory response. We were able to quantify six cytokines in the CSF of our cohort of HIV-infected women and observed that the pro-inflammatory IL-2, IFN $\gamma, \mathrm{TNF} \alpha$, and the antiinflammatory IL-10 were associated with the presence and severity of HAND. These results are consistent with other studies that show an association between cognitive function and increased levels of IFN $\gamma$ and TNF $\alpha$ in the CSF of several ethnic populations of people living with HIV (PLH) $(13,48-$ 50). Experimental evidence also shows that higher levels of IL-6 in CSF of HIV-infected patients with HAND confirm its specific role as mediator of neuroinflammation during chronic HIV inflammation (51). In addition, several studies identified possible pathways involved in the generation of IL-6 from brain microvascular endothelial cells, as well as astrocytes (52, 53). Interestingly, when the neuronal cells were exposed to these elevated cytokines, only $\mathrm{TNF} \alpha$ was able to induce higher secretion of sIR from neuronal cells. This finding was supported by the fact that $\mathrm{R} 7050$, a TNF $\alpha$ receptor blocker, when added to the culture medium for $24 \mathrm{~h}$, antagonized the effects of TNF $\alpha$ in sIR secretion. This is in accordance with previous reports showing that $\mathrm{TNF} \alpha$ can induce the secretion of other soluble receptors in the culture medium (54).

Cognitive impairment in $\mathrm{HIV}$-infected patients may be caused directly by the action of the HIV virus or its well-known auxiliary proteins (55). HIV-1 Tat, Rev, Nef, Vif, Vpr, and Vpu can promote neurotoxicity through several mechanisms which result in neuronal dysfunction and cell loss $(16,56)$. Of these viral 


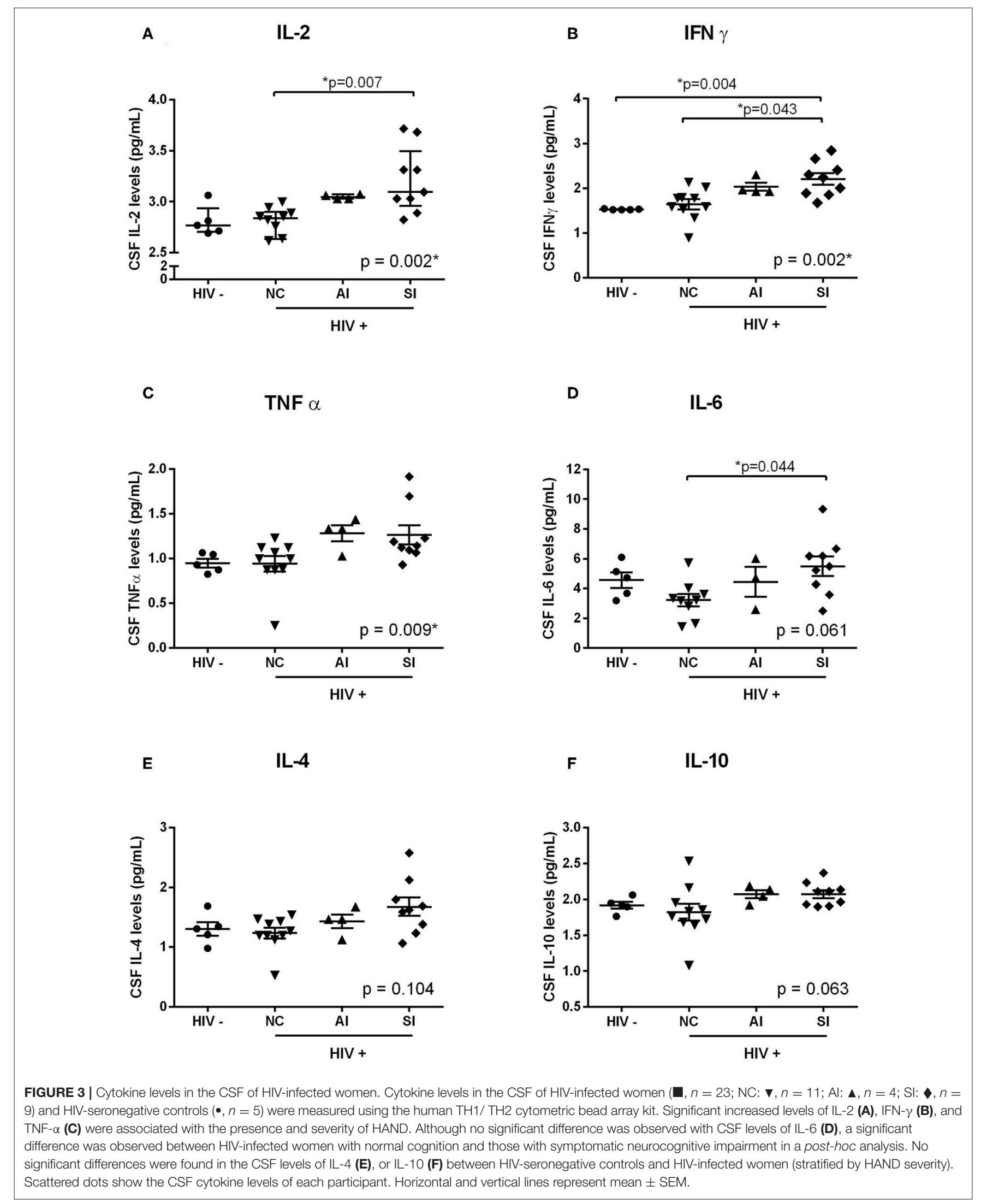




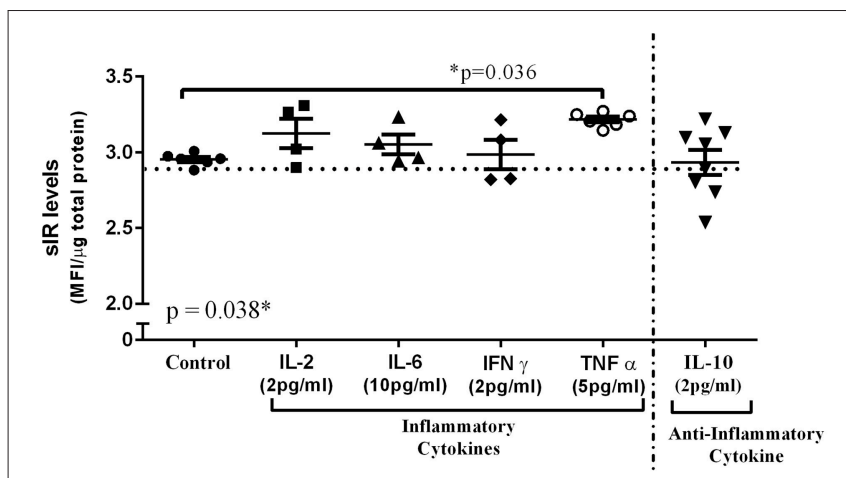

FIGURE 4 | Neuronal sIR levels after incubation with individual cytokines. Cultured SH-SY5Y cells were incubated for $24 \mathrm{~h}$ with all elevated cytokines previously quantified in the CSF of HIV-infected patients (IL-2 [ $\mathbf{\square}, n=4]$; IL-6 $[\boldsymbol{\Lambda}, n=4] ;$ IFN- $\gamma[\boldsymbol{\vee}, n=4] ;$ TNF- $\alpha[0, n=6]$; and IL-10 [ $\mathbf{\nabla}, n=8])$. Of these cytokines only TNF $\alpha$ was able to significantly increase the levels of $\mathrm{SIR}$ secreted from neurons compared to those that were untreated $(\bullet, n=6)$. Scattered dots show the secreted sIR levels quantified from each well. Horizontal and vertical lines represent mean \pm SEM.

proteins, HIV-1 Tat (one of the first HIV proteins to be expressed after infection occurs), has been shown to have a deleterious role in the development and progression of HAND. Indeed, HIV-1 Tat protein can be released from infected cells even in patients who are adequately treated with antiretroviral drugs to affect HIV non-permissive cells such as neurons $(18,57)$. In our study, we found that HIV-1 Tat increased the secretion of sIR from neuronal cells and R7050 was able to antagonize this effect. The mechanisms employed by HIV-1 Tat on sIR secretion can be explained by its interaction with the toll-like receptor 4 (TLR4). Studies have revealed that HIV-1 Tat interacts physically (with high affinity) with TLR4-MD2 to promote TNF $\alpha$ expression (11). Other studies also show that HIV-1 Tat can induce the secretion of TNF $\alpha$ and IL1 $\beta$ from U87 glioma cells (58). Thus, it is then conceivable that the autocrine effects of TNF $\alpha$ induced by HIV-1 Tat can be conceptualized as a part of the physiological process used by the toxin to regulate neuronal function during HIV infection. Previously we published that sIR acted as a scavenger receptor for insulin promoting intracellular insulin resistance (42). In this study, we observed that the release of sIR is induced by Tat and TNF $\alpha$ suggesting an effect on the insulin signaling pathway and contributing to the neuropathogenesis of HAND. These findings suggest that the replacement of insulin alone such as intranasal insulin may not be sufficient for treatment of these patients.

Our study has several limitations. First, the sample size is small, particularly for the sub-group analyses that we performed. We believe that our sub-group comparisons were sufficiently sized to generate meaningful conclusions; however, our findings should be interpreted with caution. The need to replicate these findings is important. Second, for the purpose of this study we focused on the role of HIV-1 Tat and inflammatory cytokines in the release of sIR from neuronal cells. The presence of glutamate in the CSF and the possible influence of TNF and Tat combination on the secretion of sIR was not measured. Third, we did not adjust for multiple comparisons in our analysis of

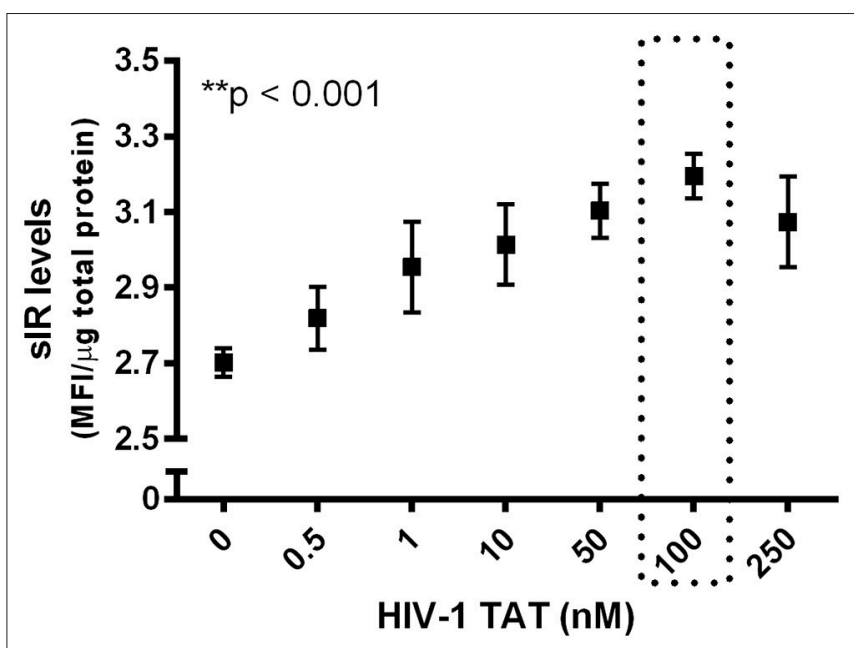

FIGURE 5 | Dose-response curve of HIV-1 Tat vs. sIR levels secreted from neuronal cells. A dose-response curve was created to determine the dose of HIV-1 Tat that would induce maximal sIR secretion ( $\mathbf{\square})$ after $24 \mathrm{~h}$ of incubation. Soluble IR secretion was quantified by ELISA. A concentration of $100 \mathrm{nM}$ induced maximal neuronal sIR secretion $(p<0.001)$. Data on the graph are presented as the mean $\pm \operatorname{SEM}(n=4$ for all data points).

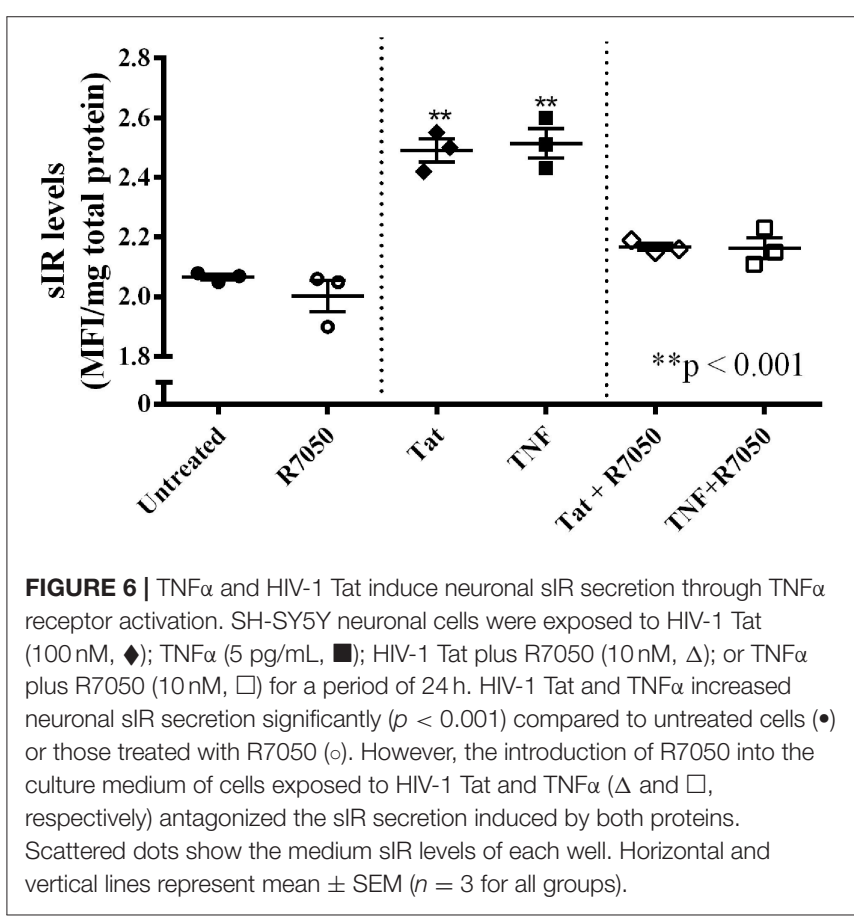

sIR secretion from neuronal cells. We believe that adjustment was not necessary for two reasons: (1) we conducted planned comparisons that each asked the same basic question, and (2) there was consistency in the results with all comparisons pointing to the same conclusion. Fourth, we only studied a cohort of women with HIV infection since our cohort was designed to study the effects of HIV in women. Further studies to address sex differences are warranted. Fifth, our study design did not consider differentiating the chronic vs. acute effects of HIV-1 Tat. Future studies comparing this effect should be considered. 
Soluble receptors, including insulin, may be secreted from cells in several forms such as intact or with an associated cell membrane. Recent studies have observed that the latter form may be secreted as a vesicle as an exosome $(59,60)$. In this study we proposed to determine the association of the sIR as measured previously in Gerena et al. $(41,42)$ and inflammation. We understand that further studies including the determination of exosomes should be performed.

Our study provides evidence that the activation of the TNF $\alpha$ receptor plays an important role in the secretion of sIR from neuronal cells. Both TNF $\alpha$ and HIV-1 Tat regulate the secretion of sIR from neuronal cells. Further studies will investigate whether the effects of HIV-1 Tat on sIR secretion are mediated by neuronal TNF $\alpha$ being released to the extracellular medium.

\section{AUTHOR CONTRIBUTIONS}

YG, RM-D, JV, AN, and VW were responsible for the conception and design of the study. YG, RM-D, AD-N, JM-Á, JS-P, LH, AN, and VW contributed to the data acquisition. RS, YG, RM-D, $\mathrm{AN}$, and $\mathrm{VW}$ were involved in the analysis and interpretation of data. YG, RM-D, and VW drafted the first version of the article. All authors revised it critically for important intellectual content. All authors gave final approval of the version to be submitted.

\section{FUNDING}

Sources of support: R01NS099036, R21MH095524, S11NS046278, U54NS043011, U54MD007587, G12MD007600, R25MH080661.

\section{ACKNOWLEDGMENTS}

We thank Joseph Steiner, Ph.D., Director of the Translational Neuroscience Center Drug Development Unit of NINDS, NIH for providing the HIV-1 Tat used in the experiments and all individuals who took part in the study.

\section{REFERENCES}

1. Fabbiani M, Ciccarelli N, Tana M, Farina S, Baldonero E, Di Cristo V, et al. Cardiovascular risk factors and carotid intima-media thickness are associated with lower cognitive performance in HIV-infected patients. HIV Med. (2013) 14:136-44. doi: 10.1111/j.1468-1293.2012.01044.x

2. Monsuez JJ, Belin C, Bouchaud O. Microvascular function in aging among women living with HIV. Curr HIV/AIDS Rep. (2016) 13:392-8. doi: 10.1007/s11904-016-0339-3

3. Pillay B, Ramdial PK, Naidoo DP. HIV-associated large-vessel vasculopathy: a review of the current and emerging clinicopathological spectrum in vascular surgical practice. Cardiovasc J Afr. (2015) 26:70-81. doi: 10.5830/CVJA-2015-017

4. Salomon J, de Truchis P, Melchior JC. Body composition and nutritional parameters in HIV and AIDS patients. Clin Chem Lab Med. (2002) 40:132933. doi: 10.1515/CCLM.2002.229

5. Cohen RA, Seider TR, Navia B. HIV effects on age-associated neurocognitive dysfunction: premature cognitive aging or neurodegenerative disease? Alzheimers Res Ther. (2015) 7:37. doi: 10.1186/s13195-015-0123-4

6. Solomon IH, De Girolami U, Chettimada S, Misra V, Singer EJ, Gabuzda D. Brain and liver pathology, amyloid deposition, and interferon responses among older HIV-positive patients in the late HAART era. BMC Infect Dis. (2017) 17:151. doi: 10.1186/s12879-017-2246-7

7. McCutchan JA, Marquie-Beck JA, Fitzsimons CA, Letendre SL, Ellis RJ, Heaton RK, et al. Role of obesity, metabolic variables, and diabetes in HIV-associated neurocognitive disorder. Neurology. (2012) 78:485-92. doi: 10.1212/WNL.0b013e3182478d64

8. Hodes RJ, Sierra F, Austad SN, Epel E, Neigh GN, Erlandson KM, et al. Disease drivers of aging. Ann N Y Acad Sci. (2016) 1386:45-68. doi: $10.1111 /$ nyas.13299

9. Nasi M, De Biasi S, Gibellini L, Bianchini E, Pecorini S, Bacca V, et al. Ageing and inflammation in patients with HIV infection. Clin Exp Immunol. (2017) 187:44-52. doi: 10.1111/cei.12814

10. Valcour VG, Shikuma CM, Shiramizu BT, Williams AE, Watters MR, Poff PW, et al. Diabetes, insulin resistance, and dementia among HIV-1-infected patients. J Acquir Immune Defic Syndr. (2005) 38:31-6. doi: 10.1097/00126334-200501010-00006

11. Ben Haij N, Planès R, Leghmari K, Serrero M, Delobel P, Izopet J, et al. HIV1 tat protein induces production of proinflammatory cytokines by human dendritic cells and monocytes/macrophages through engagement of TLR4MD2-CD14 complex and activation of NF-kappaB pathway. PLoS ONE. (2015) 10:e0129425. doi: 10.1371/journal.pone.0129425

12. Deeks SG, Tracy R, Douek DC. Systemic effects of inflammation on health during chronic HIV infection. Immunity. (2013) 39:633-45. doi: 10.1016/j.immuni.2013.10.001

13. Yuan L, Qiao L, Wei F, Yin J, Liu L, Ji Y, et al. Cytokines in CSF correlate with HIV-associated neurocognitive disorders in the post-HAART era in China. $J$ Neurovirol. (2013) 19:144-9. doi: 10.1007/s13365-013-0150-5

14. Jones $\mathrm{M}$, Olafson $\mathrm{K}$, Del Bigio MR, Peeling J, Nath A. Intraventricular injection of human immunodeficiency virus type 1 (HIV-1) tat protein causes inflammation, gliosis, apoptosis, and ventricular enlargement. J Neuropathol Exp Neurol. (1998) 57:563-70. doi: 10.1097/00005072-199806000-00004

15. Olivetta E, Percario Z, Fiorucci G, Mattia G, Schiavoni I, Dennis C, et al. HIV-1 Nef induces the release of inflammatory factors from human monocyte/macrophages: involvement of Nef endocytotic signals and NF-kappa B activation. J Immunol. (2003) 170:1716-27. doi: 10.4049/jimmunol.170.4.1716

16. Nath A. Human immunodeficiency virus (HIV) proteins in neuropathogenesis of HIV dementia. J Infect Dis. (2002) 186 (Suppl. 2):S193-8. doi: 10.1086/344528

17. Harezlak J, Buchthal S, Taylor M, Schifitto G, Zhong J, Daar E, et al. Persistence of HIV-associated cognitive impairment, inflammation, and neuronal injury in era of highly active antiretroviral treatment. AIDS. (2011) 25:625-33. doi: 10.1097/QAD.0b013e3283427da7

18. Johnson TP, Patel K, Johnson KR, Maric D, Calabresi PA, Hasbun R, et al. Induction of IL-17 and nonclassical T-cell activation by HIV-Tat protein. Proc Natl Acad Sci USA. (2013) 110:13588-93. doi: 10.1073/pnas.13086 73110

19. Chen P, Mayne M, Power C, Nath A. The Tat protein of HIV-1 induces tumor necrosis factor-alpha production. Implications for HIV1-associated neurological diseases. J Biol Chem. (1997) 272:22385-8. doi: $10.1074 /$ jbc. 272.36 .22385

20. Kumar A, Abbas W, Herbein G. TNF and TNF receptor superfamily members in HIV infection: new cellular targets for therapy? Mediators Inflamm. (2013) 2013:484378. doi: 10.1155/2013/484378

21. Olmos G, Llado J. Tumor necrosis factor alpha: a link between neuroinflammation and excitotoxicity. Mediators Inflamm. (2014) 2014:861231. doi: 10.1155/2014/861231

22. Hong S, Banks WA. Role of the immune system in HIV-associated neuroinflammation and neurocognitive implications. Brain Behav Immun. (2015) 45:1-12. doi: 10.1016/j.bbi.2014.10.008

23. Kronfol Z, Remick DG. Cytokines and the brain: implications for clinical psychiatry. Am J Psychiatry. (2000) 157:683-94. doi: 10.1176/appi.ajp.157.5.683 
24. Toborek M, Lee YW, Pu H, Malecki A, Flora G, Garrido R, et al. HIV-Tat protein induces oxidative and inflammatory pathways in brain endothelium. J Neurochem. (2003) 84:169-79. doi: 10.1046/j.1471-4159.2003.01543.x

25. Banks WA, Robinson SM, Nath A. Permeability of the bloodbrain barrier to HIV-1 Tat. Exp Neurol. (2005) 193:218-27. doi: 10.1016/j.expneurol.2004.11.019

26. Buscemi L, Ramonet D, Geiger JD. Human immunodeficiency virus type1 protein Tat induces tumor necrosis factor-alpha-mediated neurotoxicity. Neurobiol Dis. (2007) 26:661-70. doi: 10.1016/j.nbd.2007.03.004

27. Agrawal L, Louboutin JP, Reyes BA, Van Bockstaele EJ, Strayer DS. HIV-1 Tat neurotoxicity: a model of acute and chronic exposure, and neuroprotection by gene delivery of antioxidant enzymes. Neurobiol Dis. (2012) 45:657-70. doi: 10.1016/j.nbd.2011.10.005

28. Price TO, Ercal N, Nakaoke R, Banks WA. HIV-1 viral proteins gp120 and Tat induce oxidative stress in brain endothelial cells. Brain Res. (2005) 1045:57-63. doi: 10.1016/j.brainres.2005.03.031

29. Beilfuss J, Berg V, Sneve M, Jorde R, Kamycheva E. Effects of a 1-year supplementation with cholecalciferol on interleukin-6, tumor necrosis factoralpha and insulin resistance in overweight and obese subjects. Cytokine. (2012) 60:870-4. doi: 10.1016/j.cyto.2012.07.032

30. Ferreira ST, Clarke JR, Bomfim TR, De Felice FG. Inflammation, defective insulin signaling, and neuronal dysfunction in Alzheimer's disease. Alzheimers Dement. (2014) 10 (Suppl. 1):S76-83. doi: 10.1016/j.jalz.2013.12.010

31. Glass CK, Olefsky JM. Inflammation and lipid signaling in the etiology of insulin resistance. Cell Metab. (2012) 15:635-45. doi: 10.1016/j.cmet.2012.04.001

32. Stephens JM, Lee J, Pilch PF. Tumor necrosis factor-alpha-induced insulin resistance in 3T3-L1 adipocytes is accompanied by a loss of insulin receptor substrate-1 and GLUT4 expression without a loss of insulin receptor-mediated signal transduction. J Biol Chem. (1997) 272:971-6. doi: 10.1074/jbc.272.2.971

33. Haeusler RA, McGraw TE, Accili D. Biochemical and cellular properties of insulin receptor signalling. Nat Rev Mol Cell Biol. (2018) 19:31-44. doi: 10.1038/nrm.2017.89

34. Griffith CM, Eid T, Rose GM, Patrylo PR. Evidence for altered insulin receptor signaling in Alzheimer's disease. Neuropharmacology. (2018) 136 (Pt B):20215. doi: 10.1016/j.neuropharm.2018.01.008

35. Valcour VG, Sacktor NC, Paul RH, Watters MR, Selnes OA, Shiramizu BT, et al. Insulin resistance is associated with cognition among HIV-1-infected patients: the Hawaii Aging With HIV cohort. J Acquir Immune Defic Syndr. (2006) 43:405-10. doi: 10.1097/01.qai.0000243119.67529.f5

36. Tebas P. Insulin resistance and diabetes mellitus associated with antiretroviral use in HIV-infected patients: pathogenesis, prevention, and treatment options. J Acquir Immune Defic Syndr. (2008) 49 (Suppl. 2):S86-92. doi: 10.1097/QAI.0b013e31818651e6

37. Nachega JB, Trotta MP, Nelson M, Ammassari A. Impact of metabolic complications on antiretroviral treatment adherence: clinical and public health implications. Curr HIV/AIDS Rep. (2009) 6:121-9. doi: 10.1007/s11904-009-0017-9

38. Bateman JM, McNeill H. Insulin/IGF signalling in neurogenesis. Cell Mol Life Sci. (2006) 63:1701-5. doi: 10.1007/s00018-006-6036-4

39. Huang CC, Lee CC, Hsu KS. The role of insulin receptor signaling in synaptic plasticity and cognitive function. Chang Gung Med J. (2010) 33:115-25.

40. Chiu SL, Cline HT. Insulin receptor signaling in the development of neuronal structure and function. Neural Dev. (2010) 5:7. doi: 10.1186/1749-81 04-5-7

41. Gerena Y, Skolasky RL, Velez JM, Toro-Nieves D, Mayo R, Nath A, et al. Soluble and cell-associated insulin receptor dysfunction correlates with severity of HAND in HIV-infected women. PLoS ONE. (2012) 7:e37358. doi: 10.1371/journal.pone.0037358

42. Gerena Y, Menéndez-Delmestre R, Skolasky RL, Hechavarria RM, Pérez S, Hilera C, et al. Soluble insulin receptor as a source of insulin resistance and cognitive impairment in HIV-seropositive women. J Neurovirol. (2015) 21:113-9. doi: 10.1007/s13365-014-0310-2

43. Wojna V, Skolasky RL, Hechavarría R, Mayo R, Selnes O, McArthur JC, et al. Prevalence of human immunodeficiency virus-associated cognitive impairment in a group of Hispanic women at risk for neurological impairment. J Neurovirol. (2006) 12:356-64.44. doi: $10.1080 / 13550280600964576$

44. Antinori A, Arendt G, Becker JT, Brew BJ, Byrd DA, Cherner M, et al. Updated research nosology for HIV-associated neurocognitive disorders. Neurology. (2007) 69:1789-99. doi: 10.1212/01.WNL.0000287431.88658.8b

45. Letendre S. Central nervous system complications in HIV disease: HIVassociated neurocognitive disorder. Top Antivir Med. (2011) 19:137-42.

46. Johnson TP, Nath A. Protocol for detection of HIV-Tat protein in cerebrospinal fluid by a sandwich enzyme-linked immunosorbent assay. Methods Mol Biol. (2016) 1354:343-52. doi: 10.1007/978-1-4939-3046-3_23

47. Papa V, Russo P, Gliozzo B, Goldfine ID, Vigneri R, Pezzino V. An intact and functional soluble form of the insulin receptor is secreted by cultured cells. Endocrinology. (1993) 133:1369-76. doi: 10.1210/endo.133.3.8396017

48. Nolting T, Lindecke A, Hartung HP, Koutsilieri E, Maschke M, Husstedt IW, et al. Cytokine levels in CSF and neuropsychological performance in HIV patients. J Neurovirol. (2012) 18:157-61. doi: 10.1007/s13365-012-0091-4

49. Perrella O, Carrieri PB, Guarnaccia D, Soscia M. Cerebrospinal fluid cytokines in AIDS dementia complex. J Neurol. (1992) 239:387-8.

50. Griffin DE, McArthur JC, Cornblath DR. Neopterin and interferon-gamma in serum and cerebrospinal fluid of patients with HIV-associated neurologic disease. Neurology. (1991) 41:69-74. doi: 10.1212/WNL.41.1.69

51. Airoldi M, Bandera A, Trabattoni D, Tagliabue B, Arosio B, Soria A, et al. Neurocognitive impairment in HIV-infected naïve patients with advanced disease: the role of virus and intrathecal immune activation. Clin Dev Immunol. (2012) 2012:467154. doi: 10.1155/2012/467154

52. Chaudhuri A, Yang B, Gendelman HE, Persidsky Y, Kanmogne GD. STAT1 signaling modulates HIV-1-induced inflammatory responses and leukocyte transmigration across the blood-brain barrier. Blood. (2008) 111:2062-72. doi: 10.1182/blood-2007-05-091207

53. Shah A, Verma AS, Patel KH, Noel R, Rivera-Amill V, Silverstein PS, et al. HIV-1 gp120 Induces expression of IL-6 through a nuclear factor-Kappa Bdependent mechanism: suppression by gp120 specific small interfering RNA. PLoS ONE. (2011) 6:e21261. doi: 10.1371/journal.pone.0021261

54. Kutsch CL, Norris DA, Arend WP. Tumor necrosis factor-alpha induces interleukin-1 alpha and interleukin-1 receptor antagonist production by cultured human keratinocytes. J Invest Dermatol. (1993) 101:79-85. doi: 10.1111/1523-1747.ep12360119

55. Li L, Li HS, Pauza CD, Bukrinsky M, Zhao RY. Roles of HIV-1 auxiliary proteins in viral pathogenesis and host-pathogen interactions. Cell Res. (2005) 15:923-34. doi: 10.1038/sj.cr.7290370

56. Haughey NJ, Mattson MP. Calcium dysregulation and neuronal apoptosis by the HIV-1 proteins Tat and gp120. J Acquir Immune Defic Syndr. (2002) 31 (Suppl. 2):S55-61. doi: 10.1097/00126334-200210012-00005

57. Bagashev A, Sawaya BE. Roles and functions of HIV-1 Tat protein in the CNS: an overview. Virol J. (2013) 10:358. doi: 10.1186/1743-422X-10-358

58. Zhao L, Pu SS, Gao WH, Chi YY, Wen HL, Wang ZY, et al. Effects of HIV-1 tat on secretion of TNF-alpha and IL-1beta by U87 cells in AIDS patients with or without AIDS dementia complex. Biomed Environ Sci. (2014) 27:111-7. doi: 10.3967/bes2014.024

59. Levine SJ. Mechanisms of soluble cytokine receptor generation', J Immunol. (2004) 173:5343-8. doi: 10.4049/jimmunol.173.9.5343

60. Levine SJ. Molecular mechanisms of soluble cytokine receptor generation. $J$ Biol Chem. (2008) 283:14177-81. doi: 10.1074/jbc.R700052200

Conflict of Interest Statement: The authors declare that the research was conducted in the absence of any commercial or financial relationships that could be construed as a potential conflict of interest.

Copyright (c) 2019 Gerena, Menéndez-Delmestre, Delgado-Nieves, Vélez, MéndezÁlvarez, Sierra-Pagan, Skolasky, Henderson, Nath and Wojna. This is an open-access article distributed under the terms of the Creative Commons Attribution License (CC $B Y)$. The use, distribution or reproduction in other forums is permitted, provided the original author(s) and the copyright owner(s) are credited and that the original publication in this journal is cited, in accordance with accepted academic practice. No use, distribution or reproduction is permitted which does not comply with these terms. 